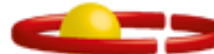 \\ Unce=UB \\ Centro Unıversıtárıo de Brasilıa
}

CENTRO UNIVERSITÁRIO DE BRASÍLIA - UniCEUB

PROGRAMA DE INICIAÇÃO CIENTÍFICA

IZABEL CRISTINA DE SENA SALES AFONSO

RELAÇÕES INTERNACIONAIS E FEMINISMO:

A ATUAÇÃO DE BERTHA LUTZ E AS REDES TRANSNACIONAIS DE

PROMOÇÃO À IGUALDADE DE GÊNERO

BRASÍLIA

2018 


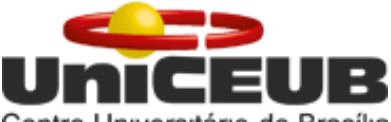

Centro Universitárıo de Brasilıa

IZABEL CRISTINA DE SENA SALES AFONSO

RELAÇÕES INTERNACIONAIS E FEMINISMO:

A ATUAÇÃO DE BERTHA LUTZ E AS REDES TRANSNACIONAIS DE

PROMOÇÃO À IGUALDADE DE GÊNERO

Relatório final de pesquisa

de Iniciação Científica

apresentado à Assessoria de

Pós-Graduação e Pesquisa.

Orientação: Aline Sapiezinskas

BRASÍLIA

2018 


\title{
RELAÇÕES INTERNACIONAIS E FEMINISMO: \\ A ATUAÇÃO DE BERTHA LUTZ E AS REDES TRANSNACIONAIS DE PROMOÇÃO À IGUALDADE DE GÊNERO
}

\author{
Izabel Cristina de Sena Sales Afonso \\ izabelsalesbel51@gmail.com (izabel.ca@sempreceub.com) \\ Professora orientadora - UniCEUB \\ Aline Sapiezinskas \\ aline.sapiens@gmail.com (aline.canani@ceub.edu.br
}

- Resumo : O presente trabalho pretende analisar a atuação feminina na política internacional multilateral, mais especificamente identificar a importância de Bertha Lutz como uma das primeiras mulheres brasileiras atuantes nas Nações Unidas, bem como demonstrar a inserção do feminismo no Brasil e que o movimento feminista pode ser considerado como uma rede transnacional e como uma comunidade epistêmica, que existe desde o século XIX. A metodologia empregada foi pesquisa bibliográfica, consultando os principais autores de referência no campo da diplomacia, da política internacional e em um sentido mais amplo, do campo de pesquisa das relações internacionais. Os resultados encontrados no presente estudo demonstram que a importância do papel da mulher dentro do contexto histórico brasileiro independe da "classe social" a qual pertence. Quanto a perspectiva feminina nas Relações Internacionais o feminismo desafia as inúmeras certezas disciplinares das Relações Internacionais, em especial no que tange às questões de segurança, política e poder. Os resultados encontrados revelam a parca pois a atuação da mulher na política internacional.

Palavras-Chave: Bertha Lutz, Redes Transnacionais, Política e Feminismo, Questões de Gênero, Relações Internacionais. 
SUMÁRIO

1-Introdução

2-Objetivos

2.1 Objetivo geral

2.2 Objetivo específico

3-Fundamentação teórica

4-Resultados e discussão

5-Conclusão

6-Referências 


\section{Introdução}

$\mathrm{O}$ Brasil do século $\mathrm{XX}$ vive um momento de renovação dentro do seu sistema monárquico com a chegada de ideias revolucionárias: liberalismo, marxismo, positivismo, advindas da Europa em especial da França, matriz do pensamento Iluminista. $\mathrm{O}$ avanço dos movimentos feministas, a profissionalização das ciências, a especialização de disciplinas e a modernização da sociedade em curso naquele período, criaram novas oportunidades para as mulheres que começaram a frequentar universidades e se inserir no mundo das ciências de forma muito mais intensa do que nos séculos anteriores. Com a propagação de tais pensamentos a sociedade brasileira começa a intensificar sua influência na luta por direitos para as mulheres, que no âmbito internacional estava em ascensão.

A modernização da década em questão é marcada pela ambiguidade. Além de trazer a preocupação com a ideia de moderno, o período em si foi o esboço, também, uma série de tensões, como a revisão dos papéis que os homens e as mulheres "deveriam" assumir, entre o moderno e o tradicional, entre o ideal burguês e os valores da população assalariada. Porém, essa tensão vai muito além da ideia de dominação, de modernização imposta. As ideias revolucionárias assimiladas pela elite intelectual brasileira, composta, por mulheres como Chiquinha Gonzaga, Nísia Floresta, Bertha Lutz, dentre outras, fizeram com que o movimento feminista se fortalecesse no país. A ligação dessas mulheres intelectuais com grupos feministas no estrangeiro demonstra à atuação das comunidades epistêmicas, a formação das redes transnacionais e como são importantes para gerar mudanças políticas, econômicas e sociais. A atuação das comunidades epistêmicas de diferentes países revela a influência das Relações Internacionais e que o Estado não é o único atuante nas mudanças existentes no âmbito global.

O conceito de comunidade epistêmica, apresentado por Peter Haas, define-se como conjunto de seres humanos disseminados em diversas esferas políticas (agências de governos, partidos políticos, grupos de interesse) atuando em questões específicas de políticas públicas. Dentro desse entendimento deve-se ressaltar a importância dessas comunidades, pois formam novas visões políticas, conduzem ao entendimento da evolução da ordem internacional, contribuem para transparência das ações, para estabilizar expectativa de outros comportamentos. O impacto dessas comunidades 
depende de diversos fatores incluindo o número de participantes, o seu poder de influência e de compreensão consensual e apresenta mais força de atuação quando tem valores morais compartilhados e quando o interesse coletivo está acima dos interesses individuais.

Nessa perspectiva a inserção do feminismo no Brasil é analisada por autoras como June Hahner, Mônica Herz e Kathryn Sikkink como uma transnational network, que existe desde o século XIX. O feminismo, como movimento social, não foi discutido apenas entre elites culturais, mas também no seio político e nas camadas pobres da sociedade brasileira da época. A desigualdade de gênero foi mundialmente praticada (Reino Unido, Estados Unidos, Argentina, Venezuela, França, Holanda, Dinamarca, etc.), mas em virtude de mudanças econômicas e políticas, como o aumento dos mercados de consumo e o surgimento da mão de obra feminina salariada, iniciam-se os movimentos feministas em países como Inglaterra e Estados Unidos e foi se propagando entre os demais países. Diante de tal campanha internacional feminista percebe-se a existência de movimentos sociais transnacionais atuando de maneira não violenta, se desenvolvendo por meio de segmentos da sociedade com objetivo comum de abolir a desigualdade entre os gêneros no âmbito internacional.

A rede transnacional se destaca por ser uma estrutura de comunicação em que diferentes seres, independente do gênero, formal ou informalmente discutem sobre cultura, sociedade e política e geram mudanças no âmbito internacional. A campanha feminista no Brasil, foi realizada por meio de uma rede transnacional composta por mulheres de grande importância e de classe social diversa, como Nísia Floresta, Leolinda Figueiredo Daltro, Bertha Lutz, entre outras, que por meio da música, da escrita, da educação e de associações feministas pugnaram pelos direitos civis e pela igualdade de gênero.

\section{Objetivo Geral:}

A pesquisa proposta objetiva a análise da participação feminina na política internacional multilateral, mais especificamente na atuação feminina brasileira nas Nações Unidas. Considera-se a importância das redes transnacionais e das comunidades epistêmicas como propagadoras de ideias que circulam no fluxo entre o internacional e nacional. Nesse sentido, será demonstrada e analisada a atuação de Bertha Lutz, como a primeira mulher brasileira a ter atuado nas Nações Unidas e será analisado o impacto 
em termos de propagação de ideias, para o Brasil e em diálogo com a Teoria Feminista em Relações Internacionais.

\section{Objetivos Específicos}

Esclarecer a participação feminina na política internacional e no campo das relações internacionais, e qual o impacto dessa participação para o Brasil.

Demonstrar a participação das mulheres na política, no âmbito da política multilateral onusiana, dando visibilidade à essa participação.

Identificar a importância de Bertha Lutz como uma das primeiras mulheres brasileiras atuantes nas Nações Unidas.

Demonstrar qual a abrangência do campo de atuação internacional das redes transnacionais, e seu impacto para o Brasil.

Estabelecer um diálogo com a Teoria Feminista em Relações Internacionais, visando identificar em que medida Bertha Lutz contribui para o movimento transnacional.

\section{Justificativa}

O projeto pretende destacar a atuação das mulheres na política internacional, pois em grande parte da literatura em diplomacia e relações internacionais há um grande foco nas figuras masculinas, e se observa uma invisibilidade e ausência no que diz respeito às mulheres e sua participação.

No que diz respeito a explanação nesta pesquisa sobre às comunidades epistêmicas e a formação das redes transnacionais, é crucial elucidar os conceitos e a importância destas para as relações internacionais e para demonstrar o movimento feminista como fenômeno de intensa participação social e de repercussões global.

Por fim, a atuação das redes transnacionais tem sido objeto de preocupação dos construtivistas na teoria das relações internacionais e dos teóricos do movimento social na política comparada. As redes que estudamos participam simultaneamente da política interna e internacional, aproveitando uma variedade de recursos, como se fossem parte de uma sociedade internacional(Keck e Kathryn Sikkink,1999) 


\section{REVISÃO BIBLIOGRÁFICA E FUNDAMENTAÇÃO TEÓRICA}

Segundo, Ana Alcantara Costa(2005), o feminismo enquanto movimento social, é um movimento essencialmente moderno, surge no contexto das ideias iluministas e das ideias transformadoras da Revolução Francesa e da Americana e se espalha, em um primeiro momento, em torno da demanda por direitos sociais e políticos. Nesse seu alvorecer, mobilizou mulheres de muitos países da Europa, dos Estados Unidos e, posteriormente, de alguns países da América Latina, tendo seu auge na luta sufragista. No Brasil, bem como em vários países latino-americanos, a exemplo do Chile, Argentina, México, Peru e Costa Rica, as primeiras manifestações aparecem já na primeira metade do século XIX, em especial por meio da imprensa feminina, principal veículo de divulgação das ideias feministas naquele momento.

Em fins do século XIX, as mulheres brasileiras incorporadas à produção social representavam uma parte significativa da força de trabalho empregada, ocupavam de forma cada vez mais crescente o trabalho na indústria, chegando a constituir a maioria da mão-de-obra empregada na indústria têxtil. Influenciadas pelas ideias anarquistas e socialistas trazidas pelos trabalhadores imigrantes espanhóis e italianos, já se podiam encontrar algumas mulheres incorporadas às lutas sindicais na defesa de melhores salários e condições de higiene e saúde no trabalho, além do combate às discriminações e abusos a que estavam submetidas por sua condição de gênero. Na primeira década do século XX, existiam organizações feministas socialistas, anarquistas e liberais em vários países da América Latina. Na maioria desses países, os processos de organização das mulheres ocorreram simultaneamente ao processo de organização das classes populares, fortemente influenciadas pelo pensamento socialista e anarquista de caráter internacional (VALDÉS, 2000; MOLYNEUX, 2003).

No Brasil, são algumas mulheres instruídas, que pertencem aos setores médios e altos, que acolhem as primeiras ideias feministas trazidas pelas publicações de Nísia Floresta Brasileira Augusta. Considerada a primeira feminista brasileira, Nísia, depois de estudar na Europa e conviver com as feministas de lá, regressa ao Brasil e publica em 1832 a tradução da obra pioneira de Mary Wollestonecraft, The vindication of the rights of women, marcando, assim, o despertar da consciência crítica da condição feminina no Brasil. Posteriormente, Nísia publica, de sua autoria, o livro Opúsculo humanitário, em 1835, e em 1842, o livro Conselhos a minha filha, nos quais defendia a necessidade da 
educação para a mulher como a única forma de garantir sua emancipação, seguindo a mesma linha de Wollestonecraft. (COSTA; SARDENBERG,1994a, p. 95).

Desde o protesto de Nísia Floresta, na década de 1830, manifestaram-se no Brasil, com mais intensidade as insatisfações femininas. Constituiu-se aqui uma imprensa feminina, cujo primeiro periódico, O Jornal das Senhoras, data de 1852, seguindo-se outros, como o de Josefina Álvares de Azevedo, que conjugava duas lutas: a do abolicionismo e a do feminismo. Algumas eram mais moderadas nas suas reivindicações, enfatizavam a importância da educação da mulher, lembrando o seu papel de mãe, ou por uma "questão de requinte espiritual" (Hahner, 1981, p. 35). Segundo, Leila Machado Coelho e Marisa Baptista(2009), Hahner aponta o fundamento positivista dos argumentos que consideravam a mulher como "a parte moral da sociedade, a base da família, que por sua vez era a pedra fundamental da nação.” (p. 85). E para o fato de que "enquanto os homens podiam esperar ter uma variedade de ambições e habilidades, as mulheres eram destinadas desde o nascimento a serem mães e esposas em tempo integral" (p. 85), em uma atitude que glorificava o lar e o casamento para as mulheres, mas não para os homens.

Em 1910 duas mulheres, Leolinda Daltro e Gilka Machado, fundaram o Partido Republicano Feminino. É curioso notar, como observa Pinto (2003), que um partido político tem como objetivo apresentar propostas e eleger seus filiados para colocá-las em prática. No entanto, nenhuma delas era elegível, ou sequer eleitora. Pretendiam, contudo, mobilizar a sociedade em torno dos direitos políticos das mulheres, através de eventos como a marcha que organizaram em 1917 pelas ruas do Rio de Janeiro, reunindo 90 (noventa) mulheres. Este partido desapareceu ao final da década de 1910.( Leila Machado Coelho e Marisa Baptista 2009, p.90)

Em 1918, Bertha Lutz, retorna ao Brasil após se formar em Biologia na Universidade de Sorbonne e em 1918 publica um artigo conclamando a mulheres a se associarem, formando uma "liga", as mulheres que entendessem que "a mulher não deve viver parasitariamente de seu sexo" antes, deve "[...] tornar-se capaz de cumprir os deveres políticos que o futuro não pode deixar de repartir com ela." (Revista da semana, 28 de dezembro de 1918, citado por Hahner, 1981:101),(Coelho e Baptista,2009). Verifica-se, assim, que o primeiro envolvimento das mulheres brasileiras com uma reivindicação por direitos sociais, não especificamente os seus, reforça seu papel social - secundário, com características de dedicação e esforço físico, numa reprodução de seu papel familiar. 
Nesse contexto percebe-se a atuação de comunidades epistêmicas, que são conceituadas por Haas(1992) como:

An epistemic community is a network of professionals with recognized expertise and competence in a particular domain and an authoritative claim to policy-relevant knowledge within that domain or issue-area. Although an epistemic community may consist of professionals from a variety of disciplines and backgrounds, they have a shared set of normative and principled beliefs, which provide a value-based rationale for the social action of community members; shared causal beliefs, which are derived from their analysis of practices leading or contributing to a central set of problems in their domain and which then serve as the basis for elucidating the multiple linkages between possible policy actions and desired outcomes.

Neste sentido, Bertha Lutz atuou como intermédiaire entre os movimentos feministas brasileiro e internacional formando uma rede transnacional. Segundo as autoras Keck e Sikkink(1999), redes transnacionais são:

significant transnationally, regionally and domestically. They may be key contributors to a convergence of social and cultural norms able to support processes of regional and international integration. By building new links among actors in civil societies, states and international organizations, they multiply the opportunities for dialogue and exchange in issues areas such as the environment and human rights, they also make international resources available to new actors in domestic political and social struggles.

As redes transnacionais investigadas pelas autoras participam simultaneamente da política interna e internacional, aproveitando uma variedade de recursos, como se fossem parte de uma sociedade internacional.

\section{Metodologia}

A escolha metodológica ocorreu em função do objeto da pesquisa definido como a atuação de Bertha Lutz nas Nações Unidas, como a primeira mulher brasileira a ter uma atuação na política internacional de âmbito multilateral. Será empregada pesquisa bibliográfica, consultando os principais autores de referência no campo da diplomacia, da política internacional e em um sentido mais amplo, do campo de pesquisa das 
relações internacionais. Visando atender aos objetivos apresentados, a pesquisa realizada é de natureza qualitativa, procurando mostrar como se deu essa atuação e qual foi o impacto da presença feminina na política internacional. Além disso, também poderão ser analisados documentos diplomáticos relativos a atas de reuniões específicas e tratados negociados que tenham contado com a participação de Bertha Lutz.

Em termos de diálogo teórico, será investigada a participação de Bertha Lutz em redes transnacionais de movimentos políticos disseminadores de valores e ideias, definindo sua comunidade epistêmica e seu pertencimento a grupos sociais específicos. Além disso, será estabelecido o diálogo com a teoria feminista de relações internacionais, cujo principal questionamento se refere à invisibilidade feminina na política internacional, bem como na esfera diplomática como um todo. Ao analisar a atuação de Bertha Lutz, será possível estabelecer quais foram as formas de atuação, bem como sua postura com relação ao pensamento feminista enquanto comunidade epistêmica.

Para traçar as linhas de conduta teórica será tomado como referência a teoria de análise das redes transnacionais, de Margaret Keck e Kathryn Sikkink (1999), que se baseia em tradições sociológicas, que se concentram em interações complexas entre atores, na construção intersubjetiva de quadros de significado e na maleabilidade de identidades e interesses. As redes transnacionais investigadas pelas autoras participam simultaneamente da política interna e internacional, aproveitando uma variedade de recursos, como se fossem parte de uma sociedade internacional. Dentro desta teoria de análise das redes transnacionais, Margaret Keck e Kathryn Sikkink(1999), demonstram o método de utilização dessas redes, information politics, symbolic politics, leverage polítics and accountability politics; os quais serão utilizados neste trabalho de pesquisa.

Ainda abordando a linha de pesquisa teórica e em conjunto com o estudo redes transnacionais, será trazido também a análise das comunidades epistêmicas de Peter Haas (1992), para verificar como os membros de uma comunidade tornam-se fortes atores a nível nacional e transnacional, à medida que os tomadores de decisão solicitam suas informações e delegam responsabilidade neles. Portanto, as comunidades epistêmicas podem contribuir para a criação e manutenção de instituições sociais que norteiam o comportamento internacional. 


\section{Resultados e discussões}

Os resultados encontrados no presente estudo demonstram que a importância do papel da mulher dentro do contexto histórico brasileiro independe da "classe social" a qual pertence. A ênfase do papel de Bertha Lutz no processo sufragista, na luta pela emancipação feminina, bem como na inclusão da igualdade de gênero no artigo primeiro da Carta da ONU demonstra a defesa de interesses regionais e universais sobre a igualdade de direitos e a importância das diplomatas latino-americanas nas relações internacionais.

Nascida em São Paulo, Bertha Lutz, filha do cientista Adolfo Lutz, teve a sua formação acadêmica na Europa, o que permitiu o contato com as ideias e os movimentos feministas da época. Após seu retorno ao Brasil, Bertha Lutz inicia seu trabalho como bióloga e por meio de publicações nos jornais e em revistas da época inicia a divulgação dos ideais feministas, sendo importante destacar que na concepção de Bertha Lutz o feminismo deveria ser propagado de forma contínua e pacífica por meio da educação, da inserção de direitos concernentes a igualdade de gênero, da conscientização política e da atuação conjunta da mulher, como é colocado na sua publicação no Rio Jornal:

\footnotetext{
“'L'union fait la force', diz a divisa belga; poderia também dizer: traz paz e torna possível a civilização... Enquanto a mulher estiver só, será sempre o ser frágil que flutua à mercê das circunstâncias, mas quando se unirem elas tornar-se-ão uma grande força...”. (Rio Jornal, março de 1919)
}

A discussão da pesquisa confirma que Bertha Lutz foi um ícone na história do feminismo brasileiro, mas o seu trabalho requer maior divulgação. Nesse sentido merece destaque o projeto "As Mulheres e a Carta das Nações Unidas" desenvolvido pelas historiadoras Fatima Sator e Elise Luhr Dietrichson, com os objetivos de demonstrar as contribuições femininas vindas dos países do Sul e de colaborar com a ONU trazendo mais informações sobre a atuação de Bertha Lutz.

Quanto a perspectiva feminina nas Relações Internacionais o feminismo desafia as inúmeras certezas disciplinares das Relações Internacionais, em especial no que tange às questões de segurança, política e poder. Nas relações internacionais, autoras como Ann Ticknner (1992) e Sandra Harding (1987) afirmam que houve uma entrada tardia 
da perspectiva feminista na disciplina. Enquanto que nas demais ciências sociais, o feminismo apresentava uma penetração crescente desde a década de 1960, nas Relações Internacionais (RI) ele entra apenas na década de 1980 - juntamente com outras perspectivas pós-positivistas, como o construtivismo, a teoria crítica e o institucionalismo histórico-sociológico - compondo o terceiro debate da disciplina. Para Tickner (2001), a entrada das feministas nas RI pode ser dividida em dois momentos, que ela classifica como "duas gerações".

A primeira geração de feministas em RI, teve como principal foco desafiar os viéses masculinos a partir dos quais se estruturavam as premissas centrais e conceitos do campo, de modo que as autoras introduziram uma crítica que evidenciava a genderização da teoria e da prática da disciplina. Já a segunda geração, deu enfoque à investigação de casos empíricos, com o objetivo de dar visibilidade as questões de gênero e da vida das mulheres.

Enquanto a primeira geração deu enfoque à desconstrução de conceitos e formas de conduzir as análises vigentes, as autoras da segunda geração são mais propositivas neste sentido, e apresentam um interesse metodológico comum pela investigação sociológica, baseada na identidade (identity-based), interpretativa ou linguística. O que há em comum entre os trabalhos das feministas em Relações Internacionais é, por um lado, usar o gênero como uma categoria de análise na condução de suas investigações, e, por outro, a centralidade que elas dão às questões metodológicas, o que pode ser uma razão explicativa da marginalidade do feminismo na disciplina, já que "o campo tende a julgar os pesquisadores nos termos de quão bem eles operacionalizam e testam as teorias existentes ao invés de valorizar as inovações teóricas e metodológicas que apresentam" (Tickner, 2005)

Para traçar as linhas de conduta teórica será tomado como referência a teoria de análise das redes transnacionais, de Margaret Keck e Kathryn Sikkink(1999), que se baseia em tradições sociológicas, que se concentram em interações complexas entre atores, na construção intersubjetiva de quadros de significado e na maleabilidade de identidades e interesses. As redes transnacionais investigadas pelas autoras participam simultaneamente da política interna e internacional, aproveitando uma variedade de recursos, como se fossem parte de uma sociedade internacional. Dentro desta teoria de análise das redes transnacionais, Margaret Keck e Kathryn Sikkink(1999), demonstram o método de utilização dessas redes, information politics, symbolic politics, leverage polítics and accountability politics; os quais serão utilizados neste trabalho de pesquisa. 
Ainda abordando a linha de pesquisa teórica e em conjunto com o estudo redes transnacionais, será trazido também a análise das comunidades epistêmicas de Peter Haas(1992), para verificar como os membros de uma comunidade tornam-se fortes atores a nível nacional e transnacional, à medida que os tomadores de decisão solicitam suas informações e delegam responsabilidade neles. Portanto, as comunidades epistêmicas podem contribuir para a criação e manutenção de instituições sociais que norteiam o comportamento internacional.

\section{Conclusão}

A inserção do feminismo no Brasil como movimento social contou com a participação de mulheres de todas as classes sociais. Mulheres como Nísia Floresta, Chiquinha Gonzaga, Bertha Lutz, dentre outras, que estavam anos luz a frente da sua época lutaram de formas diversas, porém com o mesmo objetivo o de lutar pela igualdade de direitos, de colocar a mulher como ser atuante, importante e capaz de transformar a sociedade global. A participação de Bertha Lutz em redes transnacionais de movimentos políticos disseminadores de valores e ideias, como a sua atuação como a primeira mulher brasileira a ter atuado nas Nações Unidas permitiu o questionamento sobre a invisibilidade feminina na política internacional, bem como na esfera diplomática. 


\section{Referências bibliográficas:}

ABREU, Maria Zina Gonçalves de. Luta das Mulheres pelo Direito de Voto. Movimentos sufragistas na Grã-Bretanha e nos Estados Unidos. Arquipélago - Revista da Universidade dos Açores. Ponto Delgada, 2a série, VI, 2002.

ALVES, Branca Moreira. Ideologia e feminismo: a luta pelo voto no Brasil. Petrópolis: Vozes, 1980.

ALVES, Branca Moreira; PITANGUY, Jacqueline. O Que é Feminismo. São Paulo: Brasiliense, 1984.

BLAY, E. A. e AVELAR, L. (org). 50 anos de feminismo: Argentina, Brasil e Chile: A construção das mulheres como atores políticos e democráticos. São Paulo: Edusp, 2017.

COSTA, S. G. Um estimulante encontro com Michel de Certeau: o feminismo tático de Bertha Lutz. Cadernos Pagu (Campinas), v.27, p.449-454, 2006.

DUBY, Georges; PERROT, Michele. História das Mulheres no Ocidente, vol. 4. O Século XIX. Eco, Umberto (1989) Com se faz uma tese. São Paulo, Ed Perspectiva

GARCIA, Carla Cristina. Breve História do feminismo. São Paulo: Claridade, 2005

HAAS, Peter, M. Introduction: epistemic communities and international policy coordination. (1992), International Organization; v 46.

HAHNER, June E. Emancipação do sexo feminino: a luta pelos direitos da mulher no Brasil, 1850-1940. Tradução de Eliane Lisboa. Florianópolis: Ed. Mulheres; Santa Cruz do Sul: EDUNISC, 2003.

HERZ, Monica, Andréa, HOFFMAN, Jana Tabak; Organizações Internacionais: História e Práticas, 2009.

KARAWEJCZYK, Mônica. As filhas de Eva querem votar. Dos primórdios da questão à conquista do sufrágio feminino no Brasil (c.1850-1932). 398 f. Tese (Doutorado em História). Universidade Federal do Rio Grande do Sul, Porto Alegre, 2013.

KECK, M. E.; SIKKINK, K. Activists beyond Borders. Advocacy Networks in International Politics. Londres: Cornell University Press, 1998. 
LAKATOS, Eva Maria; MARCONI, Marina de Andrade. Fundamentos de metodologia científica. 5. ed. São Paulo: Atlas, 2003.

LÔBO, Y. Bertha Lutz. Recife: Fundação Joaquim Nabuco; Editora Massagana, 2010.

MIRANDA, Guilherme Gantois de. Berta Lutz: cientista e feminista em luta pela emancipação da mulher. Seminário Internacional Fazendo Gênero. Florianópolis, 2006.

PERROT, Michelle. Minha HIstória das Mulheres. São Paulo: Contexto, 2016.

PINSKY, C. B., DEL PRIORE, M. História das mulheres no Brasil. São Paulo: Contexto, 2000.

PINSKY, C. B.; PEDRO, J. (Orgs.). Nova história das mulheres no Brasil. São Paulo: Contexto, 2012.

PRIORE, Mary. PINSKY, Carla. História das Mulheres no Brasil. São Paulo:Contexto, 2015.

RUPP, Leila J. “Worlds of Women: The Making of an International Women's Movement

SCHUMAHER, Schuma; BRAZIL, Érico Vital. Dicionário Mulheres do Brasil. Rio de Janeiro, Jorge Zahar Editor, 2000.

SOIHET, Rachel. O Feminismo Tático de Bertha Lutz. Florianópolis: Editora Mulher, 2006, p.133. 2

SOIHET, R.; PEDRO, J. A emergência da pesquisa da história das mulheres e das relações de gênero. Revista Brasileira de História. São Paulo, v.27 n.54, p.281-300. 2007.

STANSELL, Christine. The feminist promise: 1792 to the present. New York: Modern Library, 2010.

TICKNER, Ann. Gender in International Relations: feminist perspectives on achieving global security. New York: Columbia INternactional Press, 1992.

Gendering World Politics. New York: Columbia International Press, 2001.

Gendering a Discipline: Some Feminist Methodological Contributions to IR, vol. 30, $\mathrm{n}^{\circ}$

4, New Feminist Approaches to Social Sciensce. The University of Chicago Press 


\section{Fontes da Internet:}

Ministério das Relações Exteriores. Disponível em: www.itamaraty.gov.br/pt-BR/planonacional-de-acao-sobre-mulheres-paz-e-seguranca/14884-bertha-lutz. Acesso em julho 2017;

Senado Federal. Disponível em : www12.senado.leg.br/noticias/entenda-o-assunto/bertha-lutz. Acesso em agosto 2017;

Era Vargas Centro de pesquisa e documentação de História Contemporânea do Brasil da Fundação Getúlio Vargas (CPDOC-FGV). Rio de Janeiro. Disponível em: cpdoc.fgv.br/producao/dossies/AEraVargas1/biografias/berta_lutz. Acesso em julho 2017;

Revista Público. Disponível em : https://www.publico.pt/2016/09/18/mundo/noticia/a-batalhade-bertha-lutz-para-por-a-mulher-na-carta-da-onu-1742593. Acesso em julho 2017

Revista Politize. Disponível em: http://www.politize.com.br/conquista-do-direito-ao-votofeminino/. Acesso em agosto; 2017 